\title{
SPREADING OF Sn-Ag SOLDERS ON FeNi ALLOYS
}

\author{
Eduardo Saiz, ${ }^{a}$ C-W. Hwang, ${ }^{b}$ Katsuaki Suganuma, ${ }^{b}$ and Antoni P. Tomsia ${ }^{a}$
}

${ }^{a}$ Materials Sciences Division

Lawrence Berkeley National Laboratory

University of California,

Berkeley, CA 94720 USA

${ }^{b}$ Institute of Scientific and Industrial Research, Osaka University

Osaka, Japan

June, 2002

Acta Materialia

Submitted

This work was supported by the Director, Office of Science, Office of Basic Energy Sciences, Division of Materials Sciences and Engineering, of the U.S. Department of Energy under Contract No. DE-AC03-76SF00098. This work was in part supported by NEDO International Joint Research Grant supervised by the Ministry of Economy, Trade and Industry of Japan. 


\title{
Spreading of Sn-Ag Solders on FeNi Alloys
}

\author{
Eduardo Saiz, ${ }^{\mathrm{a}} \mathrm{C}-\mathrm{W}$. Hwang, ${ }^{\mathrm{b}}$ Katsuaki Suganuma, ${ }^{\mathrm{b}}$ and Antoni P. Tomsia ${ }^{\mathrm{a}}$ \\ ${ }^{a}$ Materials Sciences Division, Ernest Orlando Lawrence Berkeley National Laboratory \\ Berkeley, CA 94720 \\ ${ }^{\mathrm{b}}$ Institute of Scientific and Industrial Research, Osaka University \\ Osaka, Japan
}

Key words: soldering, iron alloys, lead-free solders, interfaces, spreading.

\begin{abstract}
The spreading of Sn-3Ag-xBi solders on Fe-42Ni has been studied using a drop transfer setup. Initial spreading velocities as fast as $\sim 0.5 \mathrm{~m} / \mathrm{s}$ have been recorded. The results are consistent with a liquid front moving on a metastable, flat, unreacted substrate and can be described by using a modified molecular-kinetic model for which the rate controlling step is the movement of one atom from the liquid to the surface of the solid substrate. Although the phase diagram predicts the formation of two Fe-Sn intermetallics at the solder/substrate interface in samples heated at temperatures lower than $513^{\circ} \mathrm{C}$, after spreading at $250^{\circ} \mathrm{C}$ only a thin FeSn reaction layer could be observed. Two interfacial layers ( $\mathrm{FeSn}$ and $\mathrm{FeSn}_{2}$ ) were found after spreading at $450^{\circ} \mathrm{C}$.
\end{abstract}

\section{Introduction}

The evolution of modern microelectronics would not have occurred without advanced soldering technology. The role of the solders is to provide good electrical and thermal 
conductivity, as well as mechanical integrity [1]. Solders are responsible for the connection of electronic devices to the outside world. Sn-Pb based solders have been traditionally used because of their easy handling, good workability, adequate mechanical properties, and low liquidus temperature [1]. However, environmental and health concerns are increasingly forcing manufacturers to eliminate lead from the microelectronics industry. Several countries are considering legislation that will restrict or altogether eliminate the use of lead [2-4]. Consequently, a considerable effort is being concentrated on the development of new lead-free solders.

The analysis of solder spreading is fundamental for the development of these new alloys [1, 2, 5-7]. The fabrication of reliable parts requires solders that wet the substrate and provide good adhesion. From the technological point of view, solder spreading is a complex phenomenon involving many factors: joint configuration, flux selection, substrate finishing, and many others [1]. The theoretical analysis of solder spreading must take into account that, in most cases, solder and substrate are not in thermodynamic equilibrium and spreading is accompanied by extensive dissolution and/or reaction at the interface.

Reactive wetting is poorly understood, and controversy persists regarding the influence of bulk interfacial reactions on spreading. Some variational treatments led to the inclusion of a reaction term in Young's equation [8-10]. More recently, a mechanistic model of reactive wetting has been proposed in which the process is divided into a series of stages: liquid flow, adsorption of reactive element, triple line ridging, and nucleation and growth of the new phase [11]. This mechanistic model focuses on the determination of the triple line structure 
and composition at each spreading stage in order to identify the driving forces for wetting as well as the processes that control spreading kinetics.

The objective of this paper is to analyze the reactive spreading of $\mathrm{Sn}-3 \mathrm{Ag}-\mathrm{xBi}$ solders on Fe42Ni alloys. Tin-silver solders are one of the candidates to replace lead-containing alloysthey have a low liquidus temperature and excellent overall properties [2-4]. The addition of bismuth reduces the alloy melting temperature and increases the tensile strength. Bismuth has also been shown to improve wetting on copper. However, large amounts of bismuth in the alloy can cause reliability problems [2-4]. Fe-42Ni is frequently used as an electrode material in electronic devices.

The study of the basic aspects of solder wetting and spreading requires separation of the various processes affecting the behavior of the molten drop in order to isolate the effects of adsorption, bulk reactions, liquid viscosity and triple line structure. High-temperature wetting experiments are generally performed using a conventional sessile drop configuration in which it is difficult both to separate the basic spreading process from additional effects (such as melting, equilibration with the atmosphere, oxide skin removal, etc.) and to record accurately the spreading kinetics. As a consequence, the spreading velocity data from such experiments are typically several orders of magnitude slower when compared to the theoretical predictions and the spreading of low temperature liquids of similar viscosities. [1, 11-13] The drop transfer setup provides a unique opportunity to systematically analyze isothermal spreading and avoid the complications related to solder melting and the use of fluxes $[14,15]$. In this work high-speed photography combined with a drop transfer setup 
was used to study spreading kinetics. The results were compared with existing models. The effect of temperature on the interfacial reactions was also examined.

\section{Experimental}

The spreading of Sn-3Ag-xBi solders (99.9 \%) on Fe-42Ni alloys was analyzed using a drop transfer setup inside an induction furnace with a tungsten heating element. The experiments were performed in $\mathrm{Ar}+5 \% \mathrm{H}_{2}$ flowing at $\sim 2 \cdot 10^{-5} \mathrm{~m}^{3} / \mathrm{s}\left[\mathrm{p}(\mathrm{Ar}) \approx 10^{5} \mathrm{~Pa}\right]$. The oxygen content of the gas leaving the furnace was measured using a $\mathrm{ZrO}_{2}$ sensor (Centorr, model 2D). For all the experiments, the oxygen content in the gas was kept lower than $1 \cdot 10^{-15} \mathrm{ppm}\left[p\left(\mathrm{O}_{2}\right)<\right.$ $\left.10^{-21} \mathrm{~atm}\right]$. Prior to the experiments, the Fe-42Ni substrates (round plates, $\sim 10 \mathrm{~mm}$ diameter, $3 \mathrm{~mm}$ height) were polished with $0.3 \mu \mathrm{m} \mathrm{Al}_{2} \mathrm{O}_{3}$ particles. The solder pieces and the substrates were cleaned with acetone and ethanol in an ultrasonic bath and dried with an air gun. The composition of the Fe-42Ni alloy is shown in Table 1.

Drop transfer spreading experiments were performed using the following procedure. A small piece of solder ( 0.1-0.2 g) was placed on an alumina substrate inside the furnace (Figure 1). The Fe-42Ni substrate was placed on a molybdenum holder situated $\sim 5-10 \mathrm{~mm}$ above the solder. Subsequently, the furnace was evacuated to a pressure of $\sim 6 \cdot 10^{-4} \mathrm{~Pa}$ and refilled with gas $\left(\mathrm{Ar}+5 \% \mathrm{H}_{2}\right)$. The gas was flown for $\sim 2$ hours before heating to assure that the required $p\left(\mathrm{O}_{2}\right)$ was reached. The assembly was heated at $25^{\circ} \mathrm{C} / \mathrm{min}$ to $450^{\circ} \mathrm{C}$. At that temperature the surface of the liquid was shiny, indicating that it was not covered by an oxide layer. When the temperature reached $450^{\circ} \mathrm{C}$, the Fe-42Ni substrate was lowered from the top and placed 
in close proximity to the liquid surface ( $\sim 1 \mathrm{~mm}$ or less). The assembly was maintained at $450^{\circ} \mathrm{C}$ for one hour. Afterwards, the substrate was lowered slowly until it just touched the drop surface and the liquid spread on it, transferring from the $\mathrm{Al}_{2} \mathrm{O}_{3}$ plate to the alloy (Figure 1). Spreading was recorded using a high-speed motion analysis system (Kodak, series SR) with a digital camera able to take up to 500 frames per second.

Analysis of spreading at a lower temperature is more closely related to the manufacturing practice. To study spreading at $250^{\circ} \mathrm{C}$, the assembly was heated to $450^{\circ} \mathrm{C}$, and after one hour at this temperature, the furnace was cooled at $\sim 10^{\circ} \mathrm{C} / \mathrm{min}$. When the temperature reached $250^{\circ} \mathrm{C}$, the substrate was lowered until it touched the surface of the liquid and spreading was recorded. In this way, the experiment can be performed before an oxide layer encapsulates the molten alloy. After $\sim 10 \mathrm{~s}$ the furnace was shut down and cooled to room temperature $(\sim 10 \mathrm{~min})$.

After the experiments, the drops were analyzed using optical and scanning electron microscopy (SEM). In some cases, the solder drop was etched away from the substrate using $\mathrm{HCl}$ and the phases present at the uncovered interface were identified using x-ray diffraction (XRD) and SEM with associated chemical analysis by energy dispersive spectroscopy (EDS). Cross sections were polished with $0.3 \mu \mathrm{m} \mathrm{Al}_{2} \mathrm{O}_{3}$ and analyzed using optical microscopy and SEM-EDS.

The dependence of the surface energy of molten SnAg solder with bismuth content and temperature was studied using the sessile drop method. Large pieces of solder $(0.5-0.8 \mathrm{~g})$ 
were placed on an alumina substrate and heated at $10^{\circ} \mathrm{C} / \mathrm{min}$ to the required temperatures (between 450 and $650^{\circ} \mathrm{C}$ ) in flowing $\mathrm{Ar}+5 \% \mathrm{H}_{2}$. A picture was taken with a CCD camera after $\sim 15$ min at each temperature, and the profile of the drop was analyzed using DropImage software (Rame Hart, USA) to calculate the surface energy.

\section{Results}

In the atmosphere and range of temperatures used in this study, the surface energy of the solders $\left(\gamma_{l v}\right)$ showed a very weak dependence with temperature, and did not depend systematically on the solders' bismuth content (Figure 2). The calculated temperature coefficients $\left(\frac{d \gamma_{l v}}{d T}\right)$ ranged between $-0.03 \mathrm{~mJ} / \mathrm{m}^{2}$ for Sn-3Ag-3Bi to $-0.4 \mathrm{~mJ} / \mathrm{m}^{2}$ for Sn-3Ag$6 \mathrm{Bi}$.

Figure 3 shows typical variations of the contact angle and drop radius with time during the spreading of Sn-3Ag-xBi drops on Fe-42Ni. At both temperatures $\left(250\right.$ and $\left.450^{\circ} \mathrm{C}\right)$, triple line velocities between 0.50 and $0.01 \mathrm{~m} / \mathrm{s}$ were recorded from 0 to $20 \mathrm{~ms}$ after the liquid solder touched the substrate surface. The drop reached a radius of $\geq 0.95 R_{f}$ (where $R_{f}$ is the final radius reached after $10 \mathrm{~s}$ at the test temperature) after $\sim 0.05 \mathrm{~s}$ (Figures $3 \mathrm{a}$ and $3 \mathrm{c}$ ). In all cases, after cooling a rough reaction layer could be seen extending ahead of the solder front (Figures $3 \mathrm{~b}$ and $3 \mathrm{~d}$ ). Some evidence of triple line pinning by the reaction layer could also be observed (Figure 3d). 
In the experiments performed at $450^{\circ} \mathrm{C}$, the final contact angles ranged between 50 and $65^{\circ}$ and the spreading behavior did not depend on the bismuth content in the solder (Figure 4b). At $250^{\circ} \mathrm{C}$, there was more variability in the measurements, but there was no systematic dependence on spreading velocities and contact angles with bismuth content (Figure 4a). The final contact angles at $250^{\circ} \mathrm{C}$ were higher, and they varied between 70 and $85^{\circ}$. In some experiments — at both temperatures, with decreasing spreading velocity — the liquid front exhibited a discontinuous movement: it stopped, the contact angle increased a few degrees, and then it jumped and resumed spreading. This "stick-slip" motion has also been observed in many low-temperature systems.

The microstructures of the solder drops, quenched from 250 or $450^{\circ} \mathrm{C}$ to room temperature, were very similar. They consisted of a eutectic microstructure with $\mathrm{Ag}_{3} \mathrm{Sn}$ lamellar grains dispersed in a tin matrix (Figure 5). As expected, bismuth precipitated in the corresponding solder alloys. Large grains of FeSn embedded into $\mathrm{FeSn}_{2}$ crystals were detected by SEMEDS and XRD in the drops quenched from $450^{\circ} \mathrm{C}$ (Figure 5).

Two reaction layers, each $\sim 3-5 \mu \mathrm{m}$ thick, at the interface between the solder and the alloy, were identified in the specimens fired at $450^{\circ} \mathrm{C}$ (Figure 6). EDS analysis showed that both layers consisted of iron and tin with a higher iron content in the layer in contact with the alloy. According to the FeSn phase diagram, these layers should be FeSn (in contact with the substrate) and $\mathrm{FeSn}_{2}$ (in contact with the solder). The interface formed at $250^{\circ} \mathrm{C}$ only showed one reaction layer (FeSn, $\sim 2-5 \mu \mathrm{m}$ thick), exhibiting in some areas rows of pores parallel to the solder/substrate interface (Figure 7). For both temperatures, elongated $\mathrm{Ni}_{3} \mathrm{Sn}_{4}$ 
crystals (incorporating some Co from the substrate) grew on top of the interfacial layers into the solder. The shape of the crystals suggests that they precipitated during cooling. Bismuth precipitates could also be observed on top of the reaction layers of the bismuth-containing solders.

\section{Discussion}

\subsection{Solder Surface Energy}

The surface energy of the solders is one of the critical parameters controlling their contact angle on the alloy. Surface energy also plays a role in several manufacturing processes such as surface mount technology and in pin-through-hole soldering. The self-alignment of surface-mounted devices, the ability to keep devices from falling off during second reflow, and the natural radius of curvature of the solder, defined as $\left(\gamma_{l \nu} \rho / \mathrm{g}\right)^{1 / 2}$ where $\rho$ is the liquid density and $\mathrm{g}$ is the acceleration of gravity, are all functions of the surface energy of the molten alloy [2]. The measured surface energies and temperature coefficients are of the order of those values reported in the literature for tin and SnAg solders $\left(400-600 \mathrm{~mJ} \cdot \mathrm{m}^{-2}\right.$ and -0.05 to $-0.20 \mathrm{~mJ} \cdot \mathrm{m}^{-2} \cdot \mathrm{K}^{-1}$ respectively) $[2,16]$. Under the experimental conditions used in this work, the addition of bismuth did not affect the surface energy of the solder. The metal surface energy is very sensitive to the atmosphere, in particular to the oxygen activity. The equilibrium oxygen partial pressure $p\left(\mathrm{O}_{2}\right)^{\text {eq }}$ for the reaction $\mathrm{Sn}+\mathrm{O}_{2} \rightarrow \mathrm{SnO}_{2}$, varies from 10-

${ }^{47} \mathrm{~atm}$ at $250^{\circ} \mathrm{C}$ to $10^{-31} \mathrm{~atm}$ at $450^{\circ} \mathrm{C}$ [17]. These partial pressures are lower than those measured during the experiments reported in this work. The fact that no solder oxidation is observed at $450^{\circ} \mathrm{C}$ needs to be explained using an active oxidation argument. As has been proposed for aluminum and other active metals, when the temperature in the furnace 
increases, the tin vapors present around the liquid metal surface react with the oxygen and bring down the oxygen partial pressure to values close to $p\left(\mathrm{O}_{2}\right)^{\mathrm{eq}}[18,19]$. In such a case, the measured surface energy corresponds to the value for that oxygen activity, and oxygen adsorption can be expected on the surface of the solder [20-23]. As the temperature increases, the oxygen activity in the furnace can reach, or even be lower than, $p\left(\mathrm{O}_{2}\right)^{\mathrm{eq}}\left(10^{-22}\right.$ atm at $\left.650^{\circ} \mathrm{C}\right)$ [17]. Depending on the values of $p\left(\mathrm{O}_{2}\right)^{\mathrm{eq}}$ and the oxygen activity in the furnace at each temperature, different amounts of oxygen adsorption on the solder surface can be expected [20-22].

A possibility exists that, in this work, the different dependences of the liquid surface energy can cancel each other. Because the oxygen activity in our furnace is fixed, the amount of oxygen adsorption on the liquid surface will decrease with temperature, since the experimental $p\left(\mathrm{O}_{2}\right)$ will be further away from $p\left(\mathrm{O}_{2}\right)^{\text {eq }}$. As a consequence, the surface energy of the solder should increase. On the other hand, for a constant level of oxygen adsorption, $\gamma_{l v}$ is expected to decrease with temperature. Both influences will cancel each other.

\subsection{Spreading Kinetics}

For a liquid in thermodynamic equilibrium with an ideally rigid and insoluble substrate, the capillary forces drive spreading towards the equilibrium angle as defined by Young's equation. Under these conditions, a spontaneous spreading of organic liquids typically occurs in time periods of seconds or less. However, the spreading of Sn-3Ag-xBi solders on $\mathrm{Fe}-42 \mathrm{Ni}$ is an example of reactive wetting in which the liquid spreads while a chemical reaction occurs at the interface. For most sessile drop experiments in high-temperature 
reactive systems, reactivity, interfacial diffusion, and other factors result in contact angles that evolve slowly over $10^{2}-10^{4} \mathrm{~s}$ [11-13]. The spreading kinetics recorded in this work for the solders agree with recent drop-transfer high-temperature experiments in which spreading rates are close to the rates reported for low viscosity aqueous or organic fluids [15, 24, 25].

A key point in the analysis of reactive spreading is the determination of the structure of the triple line. The experimental evidence suggests that in several systems [11,26], nucleation of the interfacial reaction product occurs behind the triple junction (the line where the solid, liquid, and gas meet). In that case, the triple junction moves on a flat, unreacted, metastable interface, and the associated metastable interfacial energies drive spreading.

While metastable interfacial energies can drive spreading in high-temperature systems, the spreading kinetics can be controlled by the motion of triple line ridges. When only the liquid is deformable in response to capillary forces, the triple line moves parallel to the solid surface. However, for many high-temperature systems this is not the case because at the spreading temperatures some diffusion or solution/precipitation occurs, and the solid is not undeformable. Complete equilibrium must involve a force balance in two directions (parallel and perpendicular to the substrate), and constant curvature surfaces must be attained (the liquid will have a lens shape or modifications owing to anisotropy of $\left.\gamma_{\mathrm{sl}}\right)$. Before that, a perturbation (a ridge) will form at the triple point and propagate to the final equilibrium state in a manner parallel to grain boundary grooving [11,27]. Depending on the physical characteristics of the system, there is a range of dynamic contact angles in which the ridge will grow at the triple junction of a liquid front moving on a flat substrate. In that case, the 
movement of the ridge attached to the triple line controls spreading kinetics. Ridge kinetics is controlled by local diffusion or solution-precipitation mechanisms, and it is expected to be much slower than spreading on a flat substrate once the ridge is larger than a few nanometers $[11,27]$. If the angle is outside the stable ridge range, the liquid will not form a ridge and will resist being pinned upon passing a ridge-like asperity $[11,27]$. The diffusional fluxes involved in the initiation of the ridge are limited by the atomic jump frequency. If the spreading velocity is too fast compared with the jump frequency, ridge formation will be suppressed even in the range in which the ridge is stable [11]. The spreading kinetics recorded in the drop transfer experiments are much faster than usually observed in reactive systems $[6,12,13,28,29]$. These fast velocities are consistent with spreading on a flat substrate (also denominated Regime I spreading) and seem incompatible with ridge controlled spreading (Regime II spreading) [11,27]. This behavior is not surprising since the experimental temperatures are lower than one third of the melting temperature of $\mathrm{Fe}-42 \mathrm{Ni}$ alloys and the mechanisms of ridge growth (diffusion or solution-precipitation) should be relatively slow. The critical velocity above which a ridge cannot grow at the triple junction has been estimated as [11]:

$$
v_{c a}=\frac{6 D_{s l}}{a}
$$

where $D_{S l}$ is the diffusion coefficient at the solid-liquid interface and $a$ is the jump distance. Using the surface diffusion coefficients reported for iron as a guide $\left(1 \cdot 10^{-15}-1 \cdot 10^{-16} \mathrm{~m}^{2} \cdot \mathrm{s}\right.$ at $450^{\circ} \mathrm{C}$ ) [30] and $a \approx 1 \mathrm{~nm}$, the critical velocity, $v_{c a}$, should be of the order of $\sim 6 \cdot 10^{-6}-6 \cdot 10^{-7}$ $\mathrm{m} / \mathrm{s}$. This critical velocity is several orders of magnitude lower than the velocities recorded 
in the experiments reported in this paper, which reinforces the idea that spreading is occurring in Regime I.

If spreading is controlled by the growth of the reaction layer, then spreading kinetics should depend on the solid state or surface diffusion of reactants across that layer. The observed fast-spreading velocities preclude simultaneous spreading and growth of a reaction layer thicker than a few nanometers. Moreover, as in other solder systems, the reaction layer is rough and composed of discrete intermetallic grains and not of a single grain growing in the direction of the triple line movement (Figures 6 and 7) [26]. Thus, it is reasonable to assume that during spreading a metastable situation exists at the triple line in which the liquid is spreading on a flat, unreacted solid surface [26]. As spreading decelerates, the reaction product can nucleate at the liquid front, the rough reaction layer pins the triple junction, and the liquid practically stops spreading. If a ridge forms at the triple junction, the ensuing drastic deceleration of the liquid front will allow for the reaction layer to reach and pass the triple junction. In all the samples cooled after $10 \mathrm{~s}$ at the test temperature, the reaction layer can be observed ahead of the triple junction.

The observed stick-slip behavior could be due to a reaction product nucleating at the triple junction when the macroscopic angle is large enough and some driving force for further advance remains. In that case, the front could be dislodged and resume spreading. Stick-slip behavior has been also observed in low-temperature systems when the spreading velocities decrease as the dynamic contact angle approaches the equilibrium value, and has been 
attributed to temporary pinning of the triple line at chemical or topographic irregularities on the substrate surface $[24,25]$.

\subsection{Models for Spreading}

The experimental evidence supports the hypothesis that the liquid solder spreads on a metastable, flat, unreacted surface. The observed spreading kinetics can be compared to existing models developed for low-temperature liquids on flat substrates. To do that, the following empirical fittings were used to establish the time dependence of the drop radius and contact angle:

$$
R=R_{1} \cdot\left(1-e^{-\frac{t}{\tau_{R}}}\right)-R_{0}
$$

$\theta=\theta_{1}+\theta_{2} \cdot e^{-\frac{t}{\tau_{\theta 1}}}+\theta_{3} \cdot e^{-\frac{t}{\tau_{\theta 2}}}$

where $R_{1}, R_{0}, \theta_{1}, \theta_{2}, \theta_{3}$, and the corresponding $\tau$ 's are the free parameters of the fitting. These fittings have been used to prepare plots of the capillary number $\left(C a=\eta \cdot v_{S} / \gamma_{l v}\right.$, where $v_{s}$ is the spreading velocity, $\eta$ is the liquid viscosity, and $\gamma_{l v}$ its surface energy) as a function of the dynamic contact angle $\left(\theta_{D}\right)$ (Figure 8 ) that have been compared to existing models for the spreading of low-temperature liquids.

The first model used is a hydrodynamic model developed by Cox and Voinov [25, 31, 32], which results in the following relationship for dynamic contact angles lower than $3 \pi / 4$ rads 
and the viscosities of the solders $(\sim 0.002 \mathrm{~Pa} \cdot \mathrm{s})$ [33]. The convention used here is that positive velocities correspond to advancing liquid fronts:

$$
C a=\frac{1}{9 \cdot \operatorname{Ln}\left(\frac{L}{L_{s}}\right)}\left(\theta_{D}^{3}-\theta_{0}^{3}\right)
$$

where $\theta_{0}$ is the static contact angle, $L$ is a characteristic capillary length, and $L_{s}$ is the slip length; $L_{\mathrm{s}}$ corresponds to a thickness of the meniscus immediately adjacent to the solid wall over which the "no-slip" boundary condition of classical hydrodynamics is relaxed. Two free parameters, $\theta_{0}$ and $L_{s}$, are used in the fitting.

The other model tested is a molecular-kinetics model developed by Blake [24, 34]. This model is an extension of Eyring's theory of reaction rate processes [35] to spreading, and it assumes that the advancing fluid molecules displace those molecules of the receding one on adsorption sites on a solid surface. In this case, the relationship between the capillary number and the dynamic contact angle can be written as:

$$
C a=\frac{2 \eta \lambda K_{\omega}}{\gamma_{l v}}\left[\sinh \left(\frac{\lambda^{2} \gamma_{l v}}{2 k T}\left(\cos \left(\theta_{0}\right)-\cos \left(\theta_{D}\right)\right)\right)\right]
$$

where $\lambda$ is the average spacing between adsorption sites and $K_{\omega}$ is a characteristic rate constant for molecular movement on the contact line: 
$K_{\omega}=\frac{k T}{h} e^{-\frac{\Delta G_{\omega}}{N k T}}$

Here $k$ and $h$ are the Boltzmann and Planck constants respectively, and $\Delta G_{\omega}$ is a free energy for wetting that derives mainly from the solid-fluid interaction.

The molecular-kinetics model can be modified to account for the viscous interaction between the fluid molecules themselves by assuming that $\Delta G_{\omega}$ has both surface and viscous contributions. For a liquid spreading against a gas, a simple relationship between the spreading velocity and the dynamic contact angle results [24]:

$C a=\frac{2 \lambda h K_{\omega}}{\mathrm{v} \gamma_{l v}}\left[\sinh \left(\frac{\lambda^{2} \gamma_{l v}}{2 k T}\left(\cos \left(\theta_{0}\right)-\cos \left(\theta_{D}\right)\right)\right)\right]$

where $\mathrm{v}$ is the volume for a unit of flow. For simple liquids, the unit of flow is a single atom or molecule, and $\mathrm{v}$ can be set equal to the molecular volume [35]. $\mathrm{K}_{\omega}, \lambda$, and $\cos \left(\theta_{0}\right)$ are the free parameters in the fitting.

All the data taken at $450^{\circ} \mathrm{C}$ follow a similar pattern, whereas more variability is observed in the spreading of alloys at $250^{\circ} \mathrm{C}$. There is no systematic dependence of spreading kinetics with the bismuth content. The variability observed at $250^{\circ} \mathrm{C}$ is probably a result of solder oxidation occurring as spreading takes place. The equilibrium $p\left(\mathrm{O}_{2}\right)$ for tin oxidation at $250^{\circ} \mathrm{C}$ is $\sim 10^{-47}$ atm [17], and after a few seconds at this temperature the drop surface 
becomes dull. During heating the oxide layer on the solder does not disappear until the temperature reaches $\sim 400^{\circ} \mathrm{C}$.

The results from the fittings are summarized in Table 2. Both the hydrodynamic and molecular-kinetics equations reproduce the experimental results well (Figure 9). The results from the hydrodynamic fitting imply a value of $L_{s} \approx 0$. Most hydrodynamic analysis of lowtemperature data will result in a slip length of microscopic but measurable dimensions (typically between 0.001 and $1 \mu \mathrm{m}$ ) $[25,31,36]$. The values of $L_{s}$ derived from our experiments are not consistent with the continuum description of spreading. It has been pointed out by Petrov and Petrov [37] and de Ruijter et al. [38] that $L_{\mathrm{s}} \approx 0$ implies that there are other sources of energy dissipation within the three-phase region in addition to the viscous one, such as those effects assumed in molecular kinetic models.

The parameters deduced from the molecular-kinetic analysis are more reasonable. The calculated distances between adsorption sites $(0.1-1.0 \mathrm{~nm})$ are, as expected, in the order of the atomic distances. The wetting activation energies calculated using Eq. 5 or 7 are similar and slightly higher than activation energies reported for viscous flow in tin $(\sim 6 \mathrm{~kJ} / \mathrm{mol})$ [35]. There is a wide range of molecular displacement frequencies reported for low-temperature liquids (from $10^{3}$ to $10^{10} \mathrm{~s}^{-1}$ ) $[24,36,38]$. The values calculated from the experiments reported in this paper are at the top of that range. The metal-metal interactions at the metastable interfaces that form during spreading are stronger than the van der Walls type of forces mostly present for low-temperature systems. Stronger solid-liquid interactions should translate into less atomic mobility for the liquid atoms attached to the interfaces and smaller 
frequencies for the movement in the direction parallel to the substrate surface [39]. However, the calculated values are at the top of the range, suggesting that the ratedetermining step is not the movement of one atom from one site to the other on the surface of the solid, but the movement of an atom from the liquid onto a site on the solid surface [39].

The analysis of spreading kinetics suggests that it is driven by metastable interfacial energies that could be associated with the unreacted interfaces. The equilibrium angles obtained from the fittings are very close to the final contact angles reached after $\sim 0.1 \mathrm{~s}$ and should correspond to the metastable value for an unreacted interface. The corresponding metastable work of adhesion will be between 0.5 and $0.7 \mathrm{~J} / \mathrm{m}^{2}$. When the dynamic contact angles are close to that value, spreading decelerates and the reaction product can nucleate at the triple junction. The reaction layer roughness and $\left(a t 250^{\circ} \mathrm{C}\right)$ the growth of the oxide layer on the drop, pin the liquid front and preclude the interpretation of the contact angle between the solders and the intermetallics using Young's equation. Furthermore, experiments carried out for long periods of time (hours) have detected a slow drift towards lower contact angles due to the combined effects of a pinned liquid front with liquid evaporation and continuing reaction [14].

\subsection{Interfacial microstructure}

The eutectic microstructure exhibited by the solder drops after cooling is what could be expected from the phase diagrams [40]. The solubility of bismuth in liquid tin at $250^{\circ} \mathrm{C}$ is higher than $90 \mathrm{wt} \%$, but because at room temperature it is well below the bismuth content in the solder, bismuth precipitates will form during cooling [40]. The iron dissolved in the alloy 
during spreading forms the tin-iron intermetallic precipitates observed in the drop after cooling from $450^{\circ} \mathrm{C}$. Only FeSn formed at the solder/substrate after $10 \mathrm{~s}$ at $250^{\circ} \mathrm{C}$ interface, even though $\mathrm{FeSn}$ and $\mathrm{FeSn}_{2}$ are stable at both temperatures. In a previous paper it was shown that both intermetallic layers have been observed in samples fired at $300^{\circ} \mathrm{C}$ for sixty minutes [14], which suggests that a larger nucleation barrier hampers the formation of $\mathrm{FeSn}_{2}$ in the samples fired for a shorter time at $250^{\circ} \mathrm{C}$. The need of an induction time for the nucleation of $\mathrm{FeSn}_{2}$ has been observed before - during the fabrication of tin plate on steel [41] and is also consistent with the large grains of FeSn trapped in $\mathrm{FeSn}_{2}$ observed in the drops formed at $450^{\circ} \mathrm{C}$. Even though its solubility is very limited (less than $1 \mathrm{wt} \%$ ), iron can dissolve in the molten solder during spreading at $450^{\circ} \mathrm{C}$. Due to the nucleation barrier for the formation of $\mathrm{FeSn}_{2}$, FeSn precipitates first during cooling and is subsequently embedded in the $\mathrm{FeSn}_{2}$ crystals. The dissolution of iron is much more limited in the samples formed at $250^{\circ} \mathrm{C}$, and iron-tin intermetallics could not be found inside the drop away from the interface. The morphology of the $(\mathrm{NiCo})_{3} \mathrm{Sn}_{4}$ platelets indicates that they formed during cooling as several quenching experiments had previously reported [14]. The cobalt present in the substrate gets incorporated in the platelets.

The porosity observed in the interfacial layer formed at $250^{\circ} \mathrm{C}$ is probably due to the unequal diffusion coefficients of iron and tin that will result in the formation of vacancies that can coalesce to form the observed pores (Kirkendall porosity) [42]. In a previous work, it was shown that this porosity has an adverse effect on the mechanical strength of the interface [14]. 


\section{Conclusions}

The spreading of Sn-3Ag-xBi solders on the Fe-42Ni substrates occurs in tens of milliseconds. Neither the spreading rates nor the surface energy of the solders depend on the bismuth content of the alloy. The experimental evidence is consistent with a liquid front moving on a metastable, flat, unreacted surface. Spreading can be analyzed using a molecular-kinetic model in which the rate-controlling step is the movement of one atom from the liquid to the solid surface. Once the reaction layer nucleates at the triple line, it pins the liquid front and stops spreading. After $\sim 10 \mathrm{~s}$ at temperature, a reaction layer covers the liquid-metal interface and grows beyond the triple line. The structure of the layer depends on the experimental temperature. After $10 \mathrm{~s}$ at $250^{\circ} \mathrm{C}$, it consists of $\mathrm{FeSn}$ and shows evidence of Kirkendall porosity that could be detrimental to the strength of the bond. After spreading at $450^{\circ} \mathrm{C}$ two intermetallic layers, $\mathrm{FeSn}$ and $\mathrm{FeSn}_{2}$, could be observed at the solder/substrate interface.

\section{Acknowledgments}

This work was supported by the Director, Office of Science, Office of Basic Energy

Sciences, Division of Materials Sciences and Engineering, of the U.S. Department of Energy under Contract No. DE-AC03-76SF00098. This work was in part supported by NEDO International Joint Research Grant supervised by the Ministry of Economy, Trade and Industry of Japan. 


\section{Figure Captions}

Figure 1. Schematic of the drop transfer setup.

Figure 2. Variation of the surface energy of Sn-3Ag-xBi solders with temperature.

Figure 3. (a) Variation of contact angle and drop radius with time during the spreading of a $\mathrm{Sn}-\mathrm{Ag}$ drop on $\mathrm{Fe}-42 \mathrm{Ni}$ at $450^{\circ} \mathrm{C}$. (b) SEM micrograph of the corresponding solder front after cooling; a rough reaction layer can be seen growing ahead of the triple junction. (c) Variation of contact angle and drop radius with time during the spreading of a Sn-Ag-6Bi drop on Fe-42Ni at $250^{\circ} \mathrm{C}$, some evidence of stick-slip behavior can be observed (arrows). (d) SEM micrograph of the corresponding solder front after cooling; there is some evidence of triple line pinning (arrow).

Figure 4. (a) Variation of contact angle and drop radius with time during the spreading of a $\mathrm{Sn}-\mathrm{Ag}-\mathrm{xBi}$ drops on $\mathrm{Fe}-42 \mathrm{Ni}$ at $250^{\circ} \mathrm{C}$. (b) Variation of contact angle and drop radius with time during the spreading of a $\mathrm{Sn}-\mathrm{Ag}-\mathrm{xBi}$ drops on $\mathrm{Fe}-42 \mathrm{Ni}$ at $450^{\circ} \mathrm{C}$.

Figure 5. (a) SEM and (b) optical micrographs of a Sn-3Ag-6Bi solder drop after spreading for $10 \mathrm{~s}$ at $450^{\circ} \mathrm{C}$ on $\mathrm{Fe}-42 \mathrm{Ni} . \mathrm{Ag}_{3} \mathrm{Sn}$ platelets and Bi precipitates are visible in the Sn matrix (a). The optical micrograph (b) shows large grains of FeSn embedded into FeSn 2 crystals (marked 1 in the SEM micrograph).

Figure 6. SEM micrograph and associated EDS analysis of the interface between Sn-3Ag$6 \mathrm{Bi}$ solder and $\mathrm{Fe}-42 \mathrm{Ni}$ after spreading for $10 \mathrm{~s}$ at $450^{\circ} \mathrm{C}$.

Figure 7. Interface between $\mathrm{Sn}-3 \mathrm{Ag}-6 \mathrm{Bi}$ solder and Fe-42Ni after spreading for $10 \mathrm{~s}$ at $250^{\circ} \mathrm{C}$. A row of pores parallel to the solder/substrate interface can be observed in the FeSn reaction layer. 
Figure 8. Plots of the capillary number versus dynamic contact angle for the spreading of Sn-3Ag-xBi solders on Fe-42Ni at $250^{\circ} \mathrm{C}$ and $450^{\circ} \mathrm{C}$.

Figure 9. Example of the fitting of the spreading kinetics of $\mathrm{Sn}-3 \mathrm{Ag}-6 \mathrm{Bi}$ solders on $\mathrm{Fe}-42 \mathrm{Ni}$ at $450^{\circ} \mathrm{C}$ using the hydrodynamic and molecular-kinetic models. 
Table 1. Composition of the Fe-42Ni alloy used in this study (wt\%).

\begin{tabular}{|c|c|c|c|c|c|c|}
\hline $\mathrm{Ni}$ and Co & $\mathrm{Fe}$ & $\mathrm{Si}$ & $\mathrm{Mn}$ & $\mathrm{C}$ & $\mathrm{S}$ & $\mathrm{P}$ \\
\hline 41.23 & 58.047. & 0.15 & 0.55 & 0.01 & 0.011 & 0.002 \\
\hline
\end{tabular}


Table 2

Parameters calculated from the fittings of the spreading data to the hydrodynamic and molecular-kinetic models (including corrections for the liquid-liquid interactions). The following values have been used in the calculations: $\eta=0.002 \mathrm{~Pa} \cdot \mathrm{s}^{-1}, \gamma_{l v}=0.45 \mathrm{~J} / \mathrm{m}^{2}, \mathrm{v}=1$ $\mathrm{nm}^{3}$

\begin{tabular}{|c|c|c|c|c|c|c|c|c|c|c|c|}
\hline \multirow[b]{2}{*}{$\begin{array}{c}\mathrm{T} \\
\left({ }^{\circ} \mathrm{C}\right)\end{array}$} & \multirow[b]{2}{*}{ Solder } & \multicolumn{2}{|c|}{$\begin{array}{l}\text { Hydrodynamic } \\
\text { model }\end{array}$} & \multicolumn{4}{|c|}{$\begin{array}{l}\text { Molecular-kinetic } \\
\text { model }\end{array}$} & \multicolumn{4}{|c|}{$\begin{array}{l}\text { Corrected Molecular-kinetic } \\
\text { model }\end{array}$} \\
\hline & & $\begin{array}{c}\theta_{0} \\
(\mathrm{deg})\end{array}$ & $\mathrm{L} / \mathrm{Ls}$ & $\begin{array}{c}\theta_{0} \\
(\operatorname{deg})\end{array}$ & $\begin{array}{c}\lambda \\
(\mathrm{nm})\end{array}$ & $\begin{array}{l}K_{\omega} \\
\left(\mathrm{s}^{-1}\right)\end{array}$ & $\begin{array}{c}\Delta G_{\omega} \\
(\mathrm{kJ} / \mathrm{mol})\end{array}$ & $\begin{array}{c}\theta_{0} \\
(\operatorname{deg})\end{array}$ & $\begin{array}{c}\lambda \\
(\mathrm{nm})\end{array}$ & $\begin{array}{l}K_{\omega} \\
\left(\mathrm{s}^{-1}\right)\end{array}$ & $\begin{array}{c}\Delta G_{\omega} \\
(\mathrm{kJ} / \mathrm{mol})\end{array}$ \\
\hline \multirow{3}{*}{250} & Sn3Ag & 83 & $2 \cdot 10^{287}$ & 83 & 0.2 & $1 \cdot 10^{8}$ & 50 & 83 & 0.2 & $5 \cdot 10^{12}$ & 8 \\
\hline & Sn-3Ag-3Bi & 77 & $8 \cdot 10^{51}$ & 76 & 0.3 & $3 \cdot 10^{9}$ & 41 & 76 & 0.3 & $5 \cdot 10^{12}$ & 11 \\
\hline & Sn-3Ag-6Bi & 73 & $6 \cdot 10^{291}$ & 71 & 0.3 & $7 \cdot 10^{7}$ & 52 & 71 & 0.3 & $2 \cdot 10^{11}$ & 17 \\
\hline \multirow{3}{*}{450} & Sn-3Ag & 63 & $5 \cdot 10^{55}$ & 61 & 0.6 & $2 \cdot 10^{7}$ & 81 & 61 & 0.6 & $1 \cdot 10^{11}$ & 31 \\
\hline & Sn3-Ag-3Bi & 63 & $5 \cdot 10^{21}$ & 60 & 0.6 & $3 \cdot 10^{7}$ & 78 & 60 & 0.6 & $1 \cdot 10^{11}$ & 31 \\
\hline & Sn3-Ag-6Bi & 59 & $7 \cdot 10^{53}$ & 59 & 0.3 & $4 \cdot 10^{8}$ & 67 & 59 & 0.3 & $9 \cdot 10^{11}$ & 21 \\
\hline
\end{tabular}




\section{References}

[1] The Mechanics of Solder Alloy Wetting \& Spreading. Yost FG, Hosking FM, Frear DR., editors. Boston: Kluwer Academic Publishers, 1993.

[2] Abtew M, Selvaduray G. Mat Sci Eng R 2000;27:95

[3] Suganuma K. Curr Opin Solid State Mat Sci 2001;5:55

[4] Suganuma K. MRS Bull 2001;26:880

[5] Warren JA, Boettinger WJ, Roosen AR. Acta Mater 1998;46:3247

[6] Yost FG, Sackinger PA, O’Toole EJ. Acta Mater 1998;46:2329

[7] Yost FG, Rye RR, Mann JA. Acta Mater 1997;45:5337

[8] Yost FG, Romig ADJ. Materials Research Society Symposium Proceedings $1988 ; 108: 385$

[9] Aksay IA, Hoge CE, Pask JA. Journal of Physical Chemistry 1974;78:1178

[10] Eustathopoulos N, Drevet B. J Phys III 1994;4:1865

[11] Saiz E, Cannon RM, Tomsia AP. Acta Mater 2000;48:4449

[12] Eustathopoulos N. Acta Mater 1998;46:2319

[13] Loehman RE, Tomsia AP. J Amer Ceram Soc 1994;77:271

[14] Hwang C-W, Suganuma K, Saiz E, Tomsia AP. Transactions of the Japanese Welding Research Institute 2001;30:167

[15] Grigorenko N, Poluyanskaya V, Eustathopoulos N, Naidich Y. Kinetics of spreading of some metal melts over covalent ceramic surfaces. In: Bellosi A, Kosmac, Tomsia AP, editors. Interfacial Science of Ceramic Joining. Boston: Kluwer Academic Publishers, 1998. p.57

[16] Keene BJ. Int Mater Rev 1993;38:157

[17] Outokumpu HSC Chemistry for Windows. 1993, Outokumpu Research: Pori, Finland [18] Marumo C, Pask JA. J Mater Sci 1977;12:223

[19] Ricci E, Passerone A. Mater Sci Eng A-Struct Mater 1993;161:31

[20] Saiz E, Cannon RM, Tomsia AP. Advan Mater 2000;12:1952

[21] Saiz E, Tomsia AP, Cannon RM. Wetting and work of adhesion in oxide/metal systems. In: Tomsia AP, Glaeser AM, editors. Ceramic Microstructures. Control at the Atomic Level.

New York: Plenum Press, 1998. p.65

[22] Passerone A, Ricci E, Sangiorgi R. J Mater Sci 1990;25:4266

[23] Sangiorgi R, Senillou C, Joud JC. Surf Sci 1988;202:509

[24] Blake TD. Dynamic contact angles and wetting kinetics. In: Berg JC, editor. Wettability. New York: Marcel Dekker Inc., 1993. p.251

[25] Kistler SF. Hydrodynamics of wetting. In: Berg JC, editor. Wettability. New York: Marcel Dekker Inc, 1993. p.311

[26] Boettinger WJ, Handwerker CA, Kattner UR. Reactive wetting and intermetallic formation. In: Yost FG, Hosking FM, Frear DR, editors. The Mechanics of Solder Alloy Wetting \& Spreading. Boston: Kluwer Academic Publishers, 1993. p.103

[27] Saiz E, Tomsia AP, Cannon RM. Acta Mater 1998;46:2349

[28] Ambrose JC, Nicholas MG, Stoneham AM. Act Met Mat 1992;40:2483

[29] Loehman RE, Tomsia AP. Act Met Mat 1992;40:S75

[30] Gjostein NA. Surface Self-Diffusion. Metal Surfaces. Metals Park, Ohio: American Society for Metals, 1963. p.99

[31] Cox RG. J Fluid Mech 1986;168:169 
[32] Voinov OV. Izv Akad Nauk SSSR Mekh Zhidk Gaza 1976; 5:76.

[33] Iida T, Guthrie RIL. The physical properties of liquid metals. Oxford: Oxford, Clarendon, 1993.

[34] Blake TD, Haynes JM. Journal of Colloids and Interfacial Science 1969;29:174

[35] Glasstone S, Laidler KJ, Eyring H. The theory of rate processes; the kinetics of chemical reactions, viscosity, diffusion and electrochemical phenomena. New York: McGraw-Hill Book Company Inc., 1941. p. 611

[36] Schneemilch M, Hayes RA, Petrov JG, Ralston J. Langmuir 1998;14:7047

[37] Petrov PG, Petrov JG. Langmuir 1992;8:1762

[38] de Ruijter MJ, DeConinck J, Blake TD, Clarke A, Rankin A. Langmuir 1997;13:7293

[39] de Ruijter MJ, Blake TD, De Coninck J. Langmuir 1999;15:7836

[40] Alloy Phase Diagrams. Baker H. editor. Materials Park, Ohio: ASM International, 1992. [41] Sarafianos N. Mater Sci Technol 1987;3:66

[42] Borg RJ, Dienes GJ. An Introduction to Solid State Diffusion. Boston: Academic Press Inc., 1988. p.360 

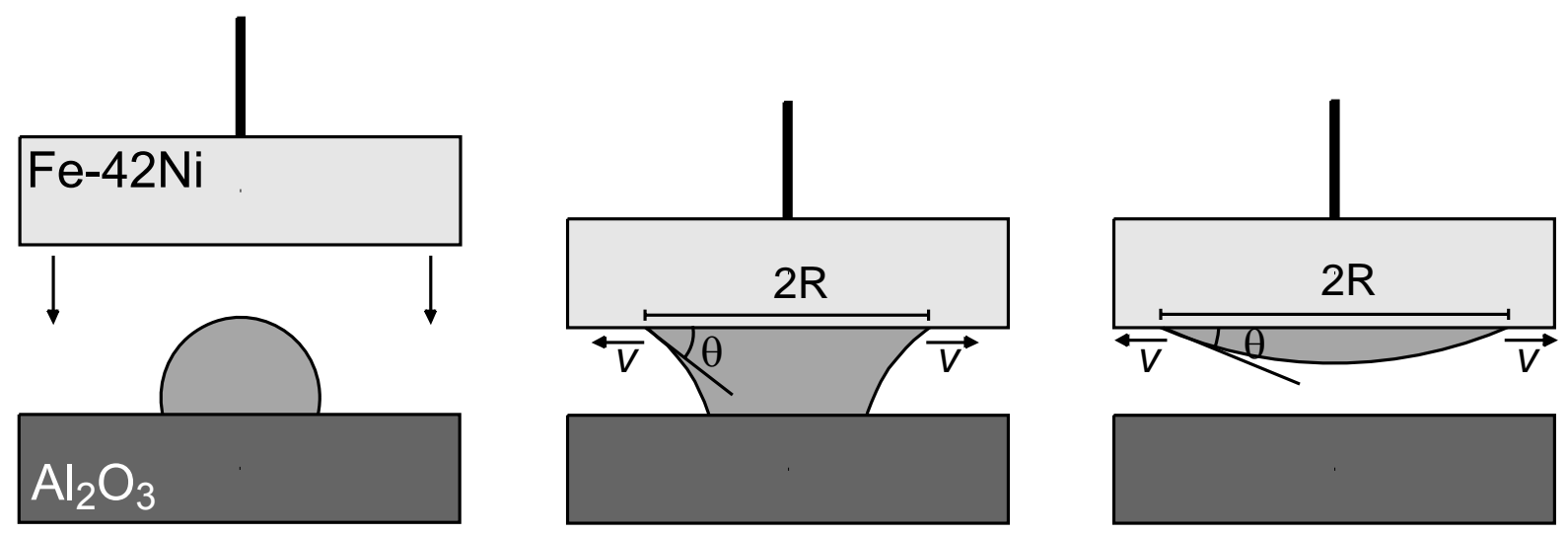

Figure 1 


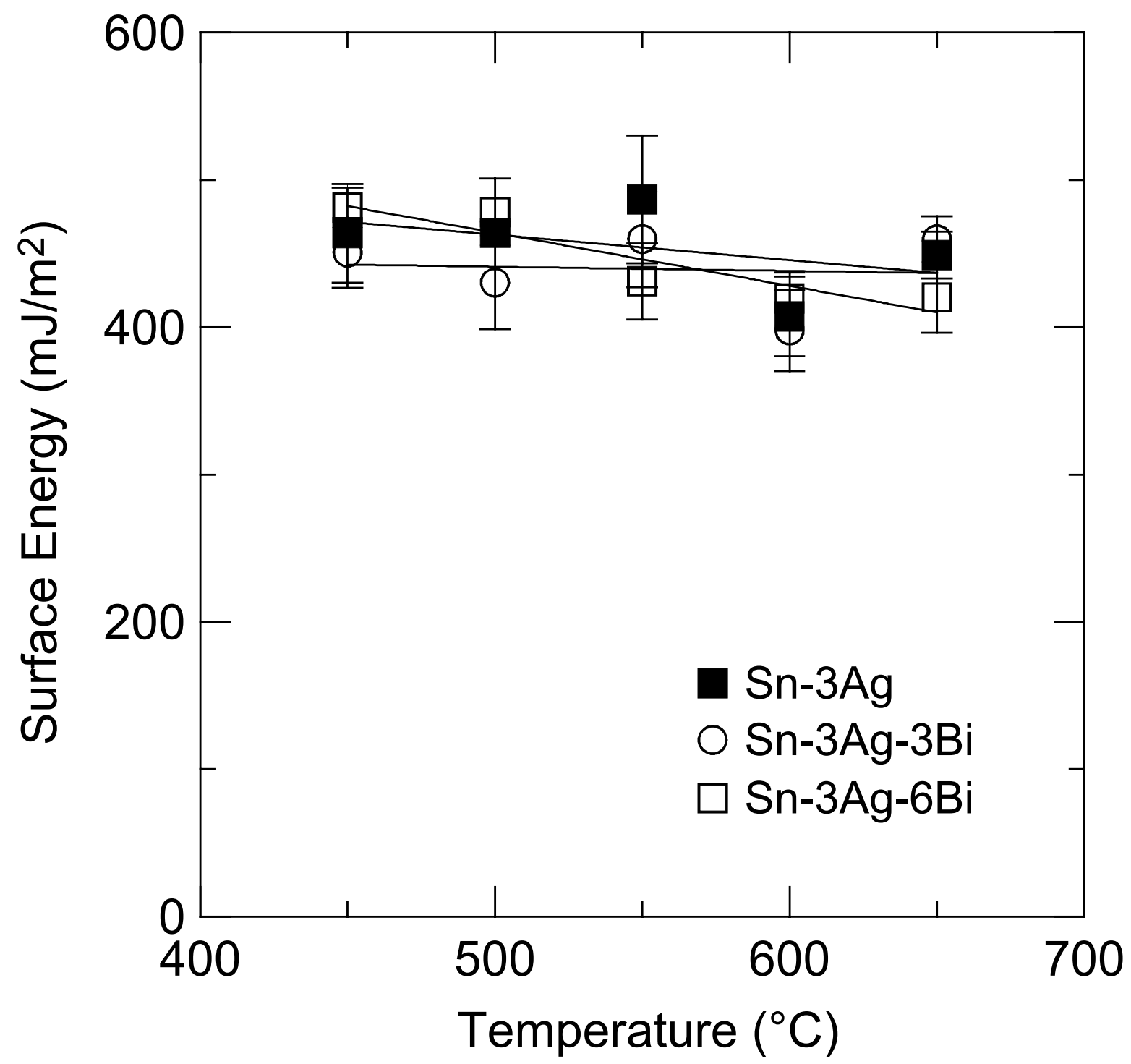

Figure 2 

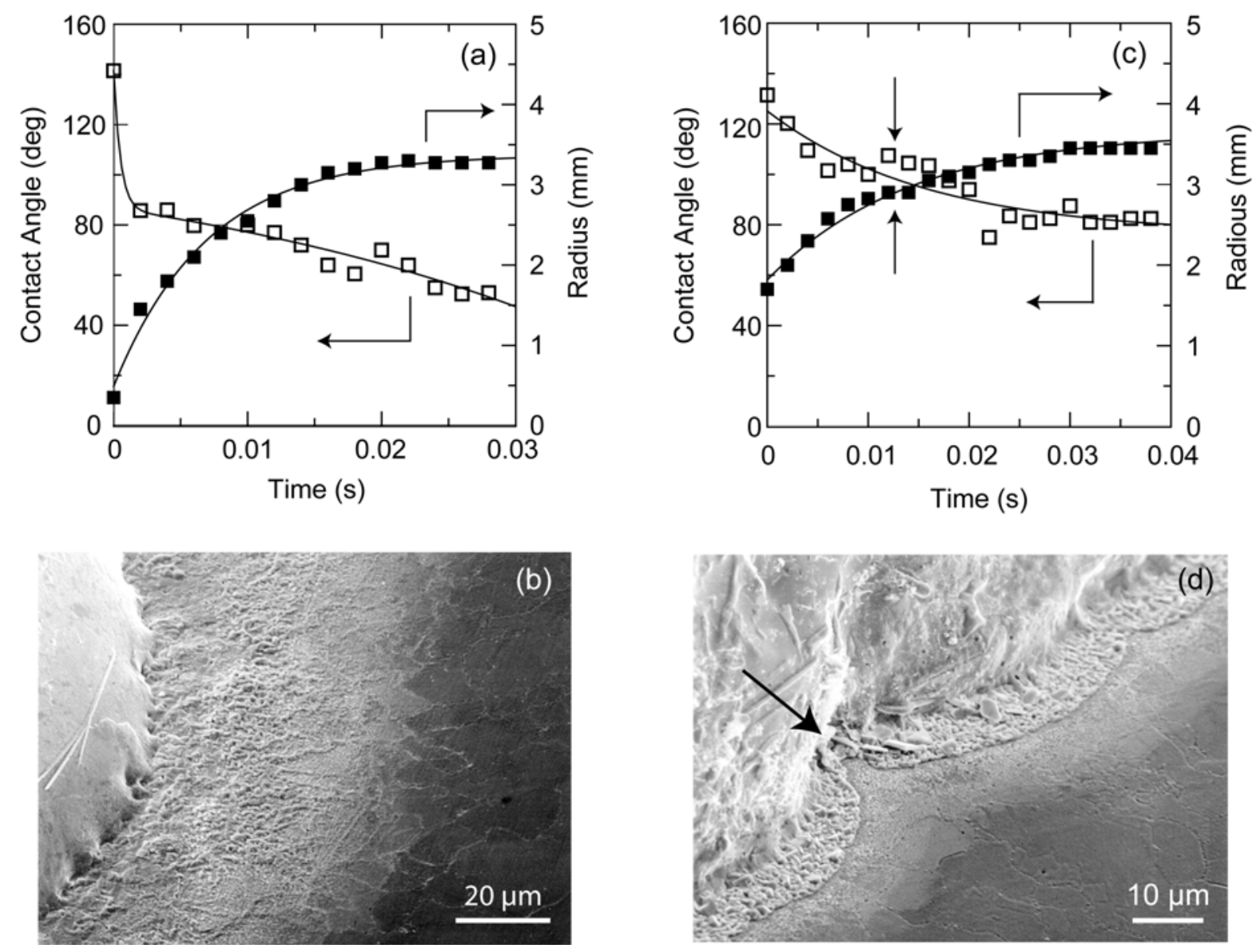

Figure 3 

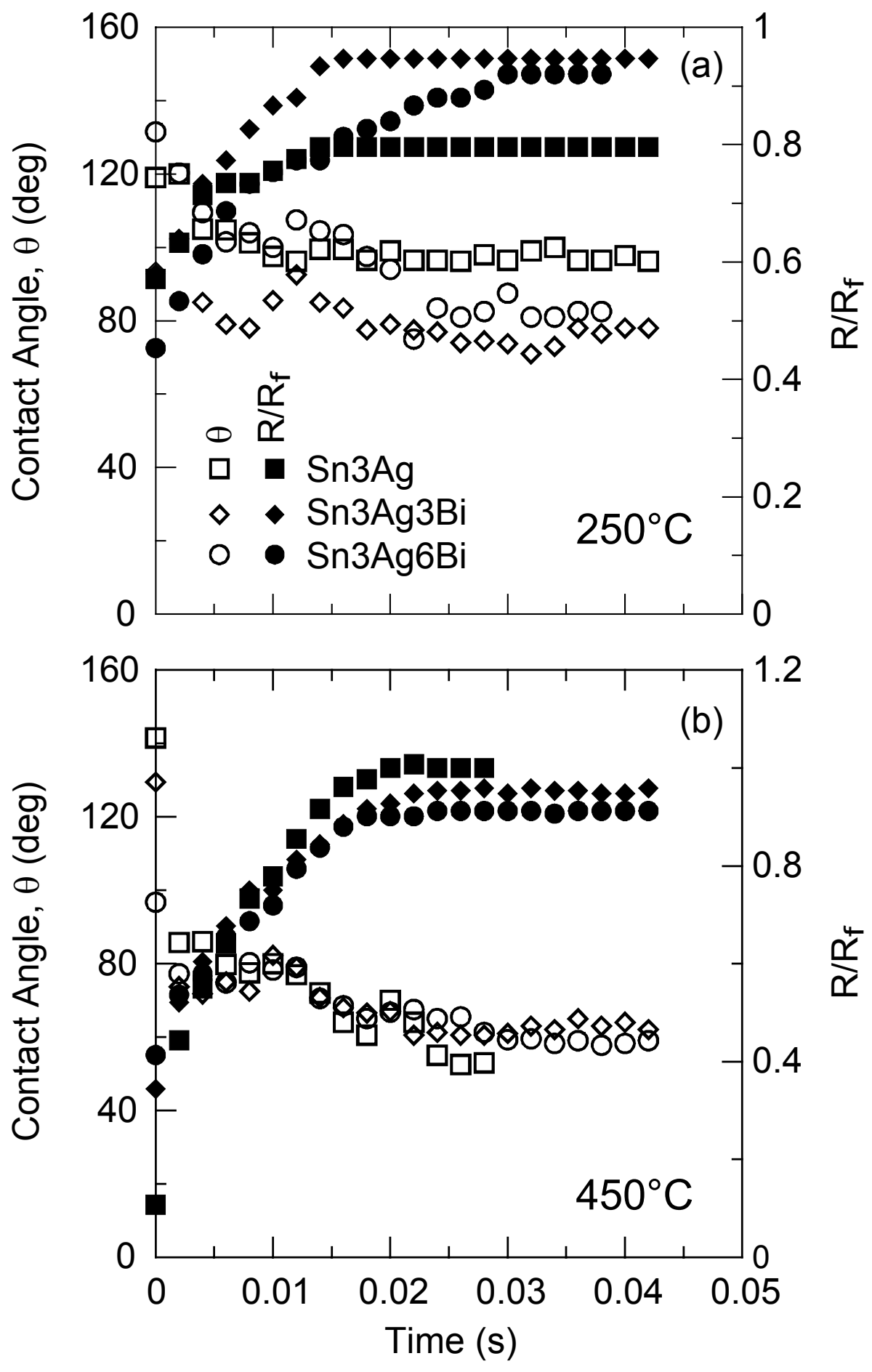

Figure 4 

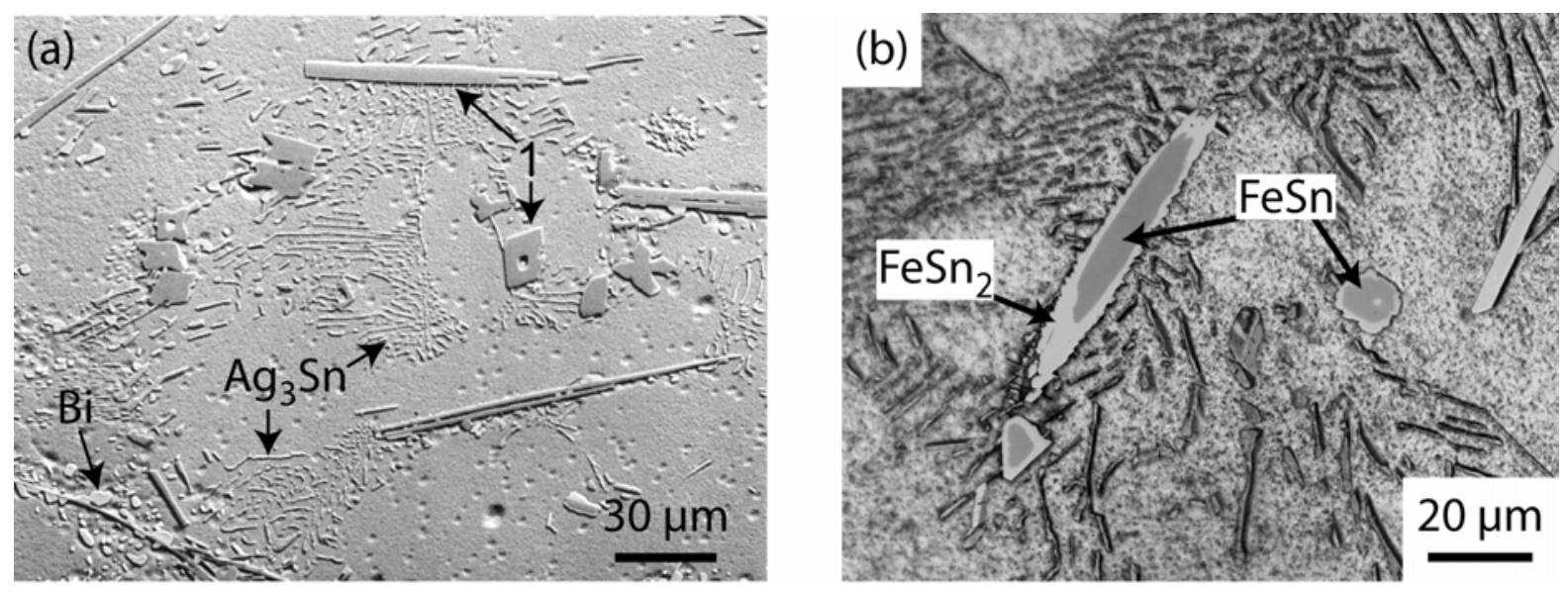

Figure 5 

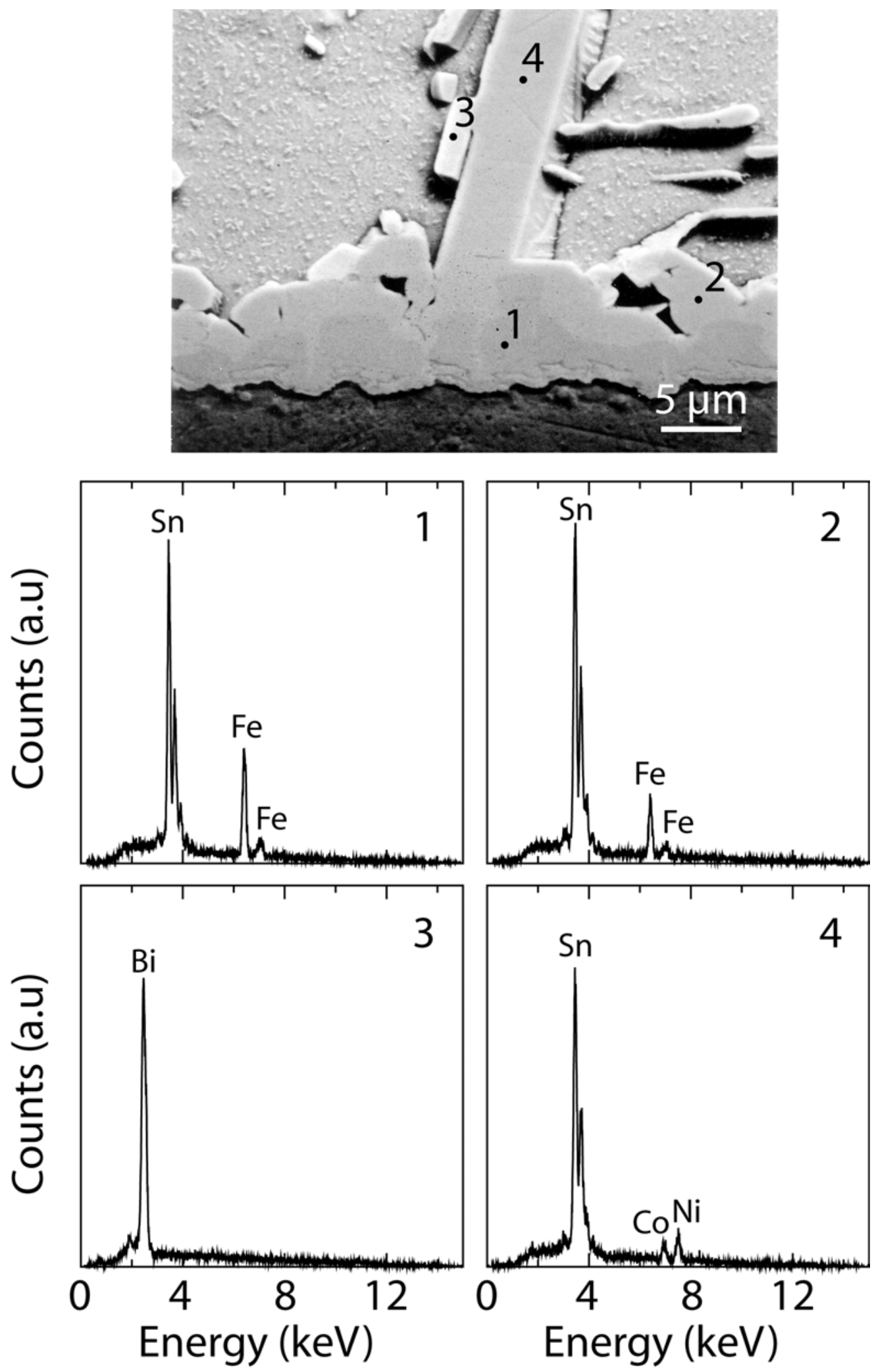

Figure 6 


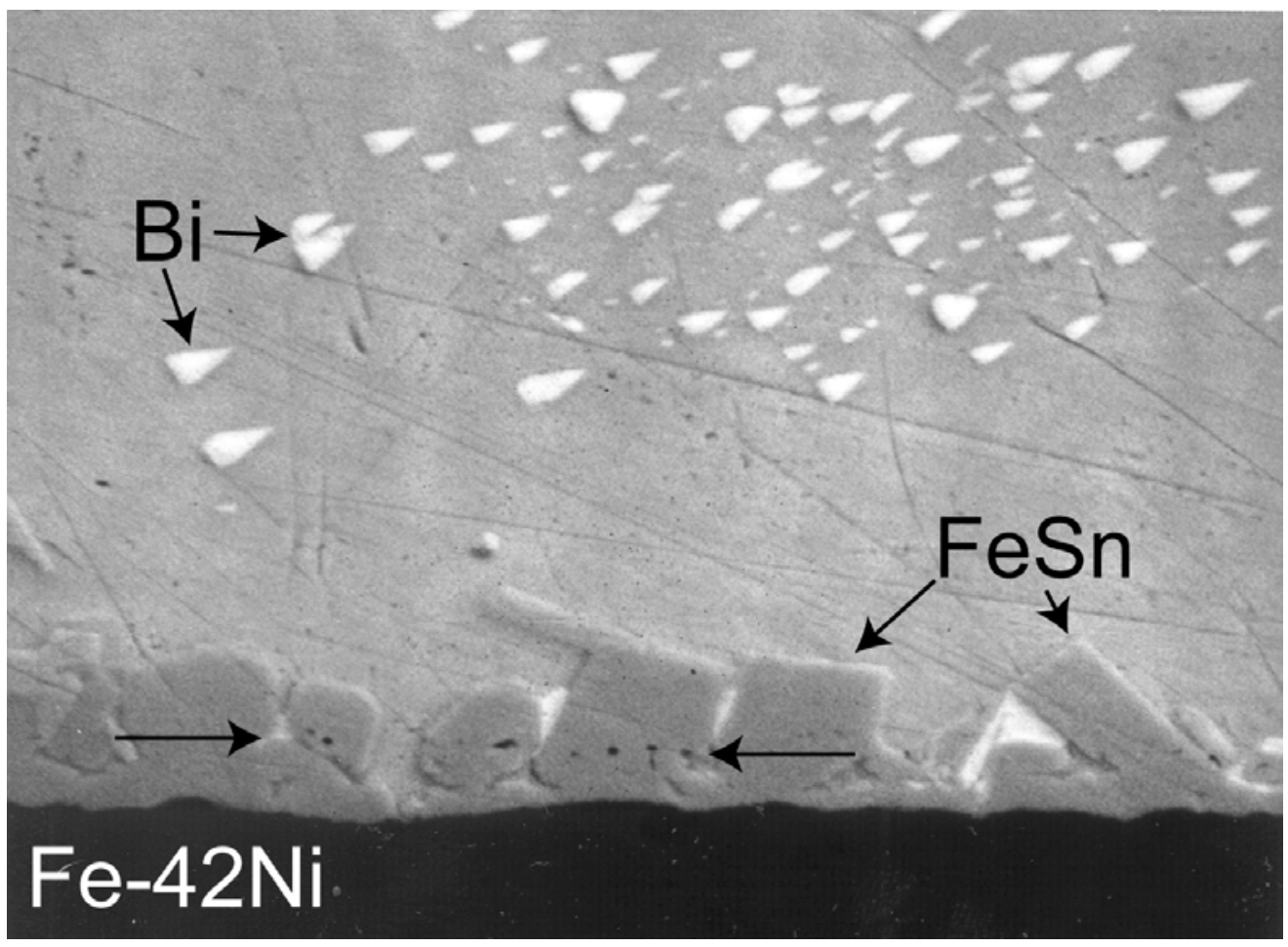

Figure 7 

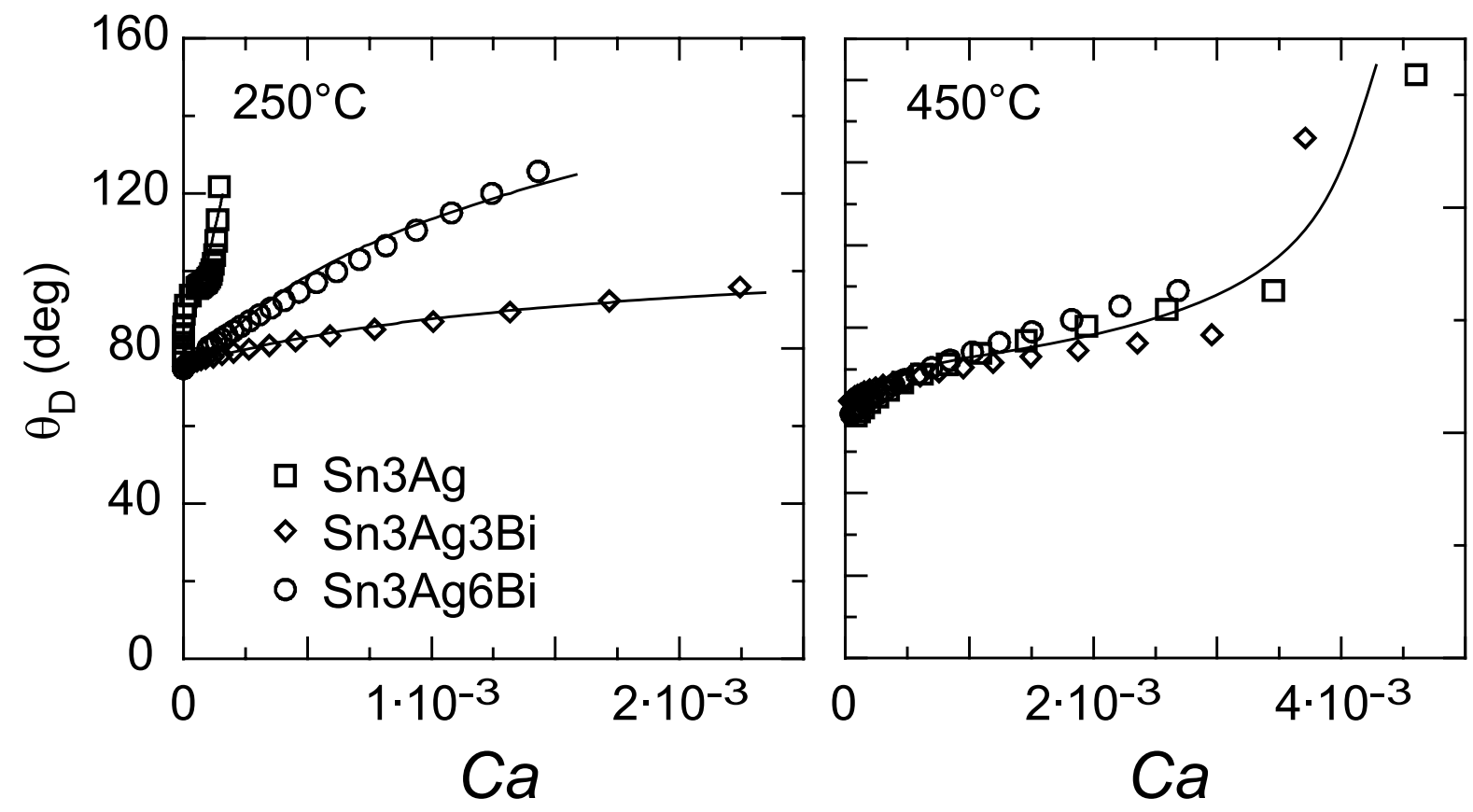

Figure 8 


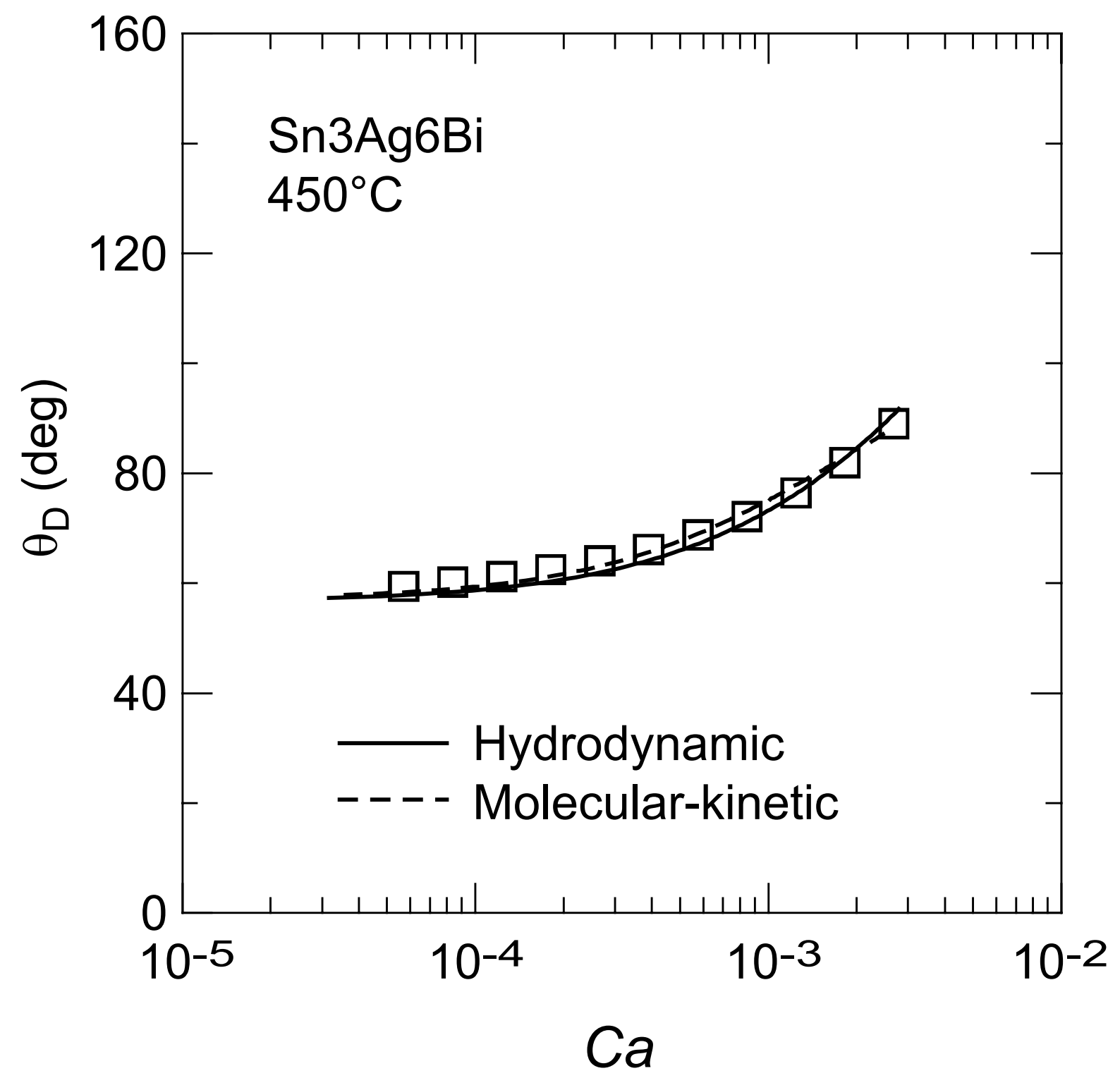

Figure 9 